

\section{O ensino de relações públicas no Brasil em relação às tecnologias digitais}

The teaching of public relations in Brazil

in relation to the digital technologies

La enseãnza de relaciones públicas

en relación a las tecnologías digitales

Valmor Rhoden

- Doutor em Comunicação pela PUC-RS

- Mestre em Extensão Rural pela Universidade Federal de Santa Maria (UFSM)

- Graduado em Relações Públicas pela UFSM

- Professor adjunto da Universidade Federal do Pampa (Unipampa)

- Coordenador do curso de Relações Públicas da Unipampa

- Autor de O Manual de cerimonial público de São Borja

- E-mail:valmor@unipampa.edu.br

9) Juliana Lima Moreira Rhoden

- Mestre em Ciências da Linguagem pela Universidade do Sul de Santa Catarina (Unisul)

- Graduada em Psicologia pela Universidade Regional do Noroeste do Estado do Rio Grande do Sul (Unijui)

- Professora assistente da Universidade Federal do Pampa (Unipampa), Campus de São Borja

• E-mail: juli.rhoden@gmail.com 


\section{Resumo}

As relações públicas completam, agora em 2014, cem anos no Brasil, sendo 47 na área do ensino. Este artigo discute 0 ensino da área no país em relação às tecnologias digitais. Discorre-se sobre a importância de repensar os currículos de maneira que possam atender à nova realidade enfrentada pelos egressos no que tange às tecnologias digitais, a partir das demandas e expectativas atuais do mundo do trabalho. Partimos do pressuposto de que o ensino não está preparando o acadêmico da área adequadamente para o cenário digital. A inserção de uma formação digital nos cursos brasileiros constitui um desafio, sendo ainda um processo isolado e incipiente. Enquanto isso, no mundo do trabalho, os egressos devem saber gerenciar a comunicação digital.

\section{PALAVRAS-CHAVE: ENSINO DE RELAÇÕES PÚBLICAS•TECNOLOGIAS DIGITAIS• FORMAÇÃO.}

\section{Abstract}

Currently, in 2014, public relations completes one hundred years in Brazil, of which 47 in the area of teaching. This article discusses the teaching of the area in our land in relation to the digital technologies. One discusses the importance of rethinking the curricula in a way that can cope with the new reality faced by graduates concerning the digital technologies, using the current demands and expectations of the working world. We begin by assuming that the teaching is not preparing adequately the student of the area for the digital scenario. The inclusion of digital skills in Brazilian courses is a true challenge, inasmuch as it is still an isolated and incipient process. Meanwhile, in the working world the graduates of the area must learn how to manage digital communication.

\section{KEYWORDS: TEACHING PUBLIC RELATIONS・DIGITAL TECHNOLOGIES・SKILLS DEVELOPMENT.}

\section{Resumen}

Las relaciones públicas completan, en 2014, cien años en el Brasil, siendo 47 en el área de la enseñanza. El presente artículo discute la enseñanza de relaciones públicas en Brasil en relación a las tecnologías digitales. En ese sentido discurre sobre la importancia de repensar los currículos de manera que puedan atender a la nueva realidad enfrentada por los graduados en lo que concierne a las tecnologías digitales, a partir de las demandas y expectativas actuales del mundo del trabajo. Partimos de la suposición que la enseñanza de relaciones públicas en Brasil no está preparando al académico del área adecuadamente para el escenario digital. La inserción de una formación digital en los cursos brasileros constituye un desafío y aún está en un proceso aislado e incipiente. Mientras tanto, en el mundo laboral, los egresados del área deben saber administrar la comunicación digital. 

ma sociedade justa e democrática é aquela que garante às pessoas recursos necessários para acesso aos meios de comunicação e informação. Da mesma forma, deve garantir educação que thes permita compreender e utilizar adequadamente ferramentas e instrumentos. Nesse contexto, se abordarmos o ensino superior, ele tem basicamente dois grandes propósitos: formar cidadãos críticos e profissionais capacitados nas suas áreas do conhecimento.

Ángel I. Pérez Gómez (2011, p. 66) apresenta alguns dados da sociedade digital atual, como a quantidade de informações que se produzem e circulam além das novas exigências para os profissionais que trabalham com informação:

Nos últimos vinte anos, produziu-se mais informação que nos cinco mil anos anteriores; a informação se duplica a cada quatro anos e cada vez de modo mais acelerado; a informação que o New York Times oferece a cada dia é maior do que uma pessoa poderia encontrar no século XVII durante toda a vida; 80 \% dos novos empregos requerem habilidades sofisticadas de tratamento da informação.

Ter domínio das tecnologias é uma questão crucial, na atualidade, para os profissionais de relações públicas ${ }^{1}$. Como as pessoas têm acesso a muitos dados, é preciso ser estrategista para selecionar as informações de interesse. Ao mesmo tempo, conseguir destaque para que a informação chegue aos públicos e propicie a bidirecionalidade na comunicação, com interatividade, faz parte de uma preparação profissional, ou seja, perpassa a questão do ensino superior.

\section{O ENSINO SUPERIOR DE RELAÇÕES PÚBLICAS: A INSERÇÃO NO CENÁRIO DIGITAL}

Claudia Herte de Moraes (2006, p. 23) já defendia que "todos os atores devem estar preparados: professores, alunos, funcionários e instituições para darem um salto qualitativo na transição tecnológica que está em curso". Ou seja, a questão não perpassa apenas a atuação do docente, mas toda a instituição de ensino e os atores envolvidos num curso superior.

Elias Machado (2007, p. 48) apresentou uma classificação interessante em relação ao ensino na era digital, concretamente do ensino de jornalismo² ${ }^{2}$ Ele utilizou o modelo preconizado pela Red Icod ${ }^{3}$, segundo a qual os cursos podem ser divididos em atualizados, reestruturados e totalmente novos no que tange à inserção no cenário digital:

1) atualizados - instituições com perfis de transformação tradicional que começam a incluir na oferta de disciplinas matérias teóricas e/ou práticas sobre temas digitais; 2) cursos reestruturados - instituições consolidadas no ensino e os conteúdos para incluir os temas digitais; 3) cursos totalmente novos-instituições novas em que os conteúdos digitais aparecem transversalmente nos planos de ensino.

Essas três categorias servem para identificar os cursos em relação ao ensino digital. 0 saber se renova constantemente e 0 ensino precisa acompanhar essa evolução. Nesse contexto, são pertinentes as indagações de Fernando Gonçalves (2002, p. 53):

Têm cumprido as relações públicas seu papel na atualidade? Como pretendem enfrentar o panorama das profundas transformações pelas quais vêm passando a sociedade, as instituições, o mercado, o cidadão, o consumidor e o próprio homem?

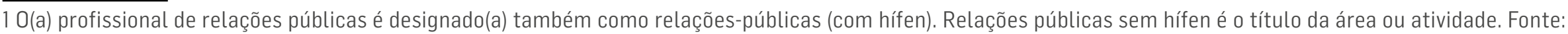
Portaria $\mathrm{n}^{0} 116$, de

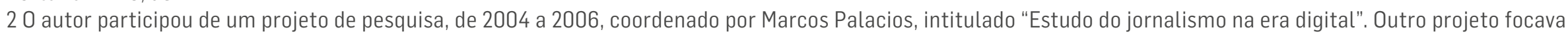

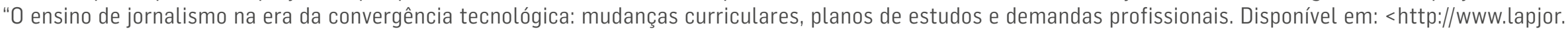
cce.ufsc.br>. Acesso em: 21 nov. 2011.

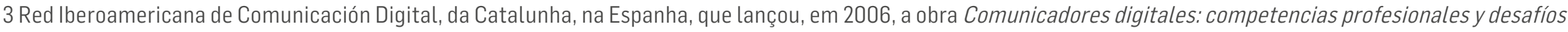
académicos. Disponível em: <http://www.bdp.org.ar/facultad/ comunicacion/archivos/2006/09/libro_en_linea.php>. Acesso em: 20 nov. 2013.
} 
Essa temática vem se prestando para constantes discussões quanto ao ensino de relações públicas no Brasil, estimuladas ainda mais com o atual estágio das inovações tecnológicas.

0 ensino da convergência deve articular, de forma harmoniosa, as instâncias do cenário digital e off-line. Nas Diretrizes Curriculares Nacionais de Relações Públicas, de 2013, há uma orientação nos princípios gerais para a observância em relação ao cenário digital nos cursos da área: "As instituições de ensino superior (IES) podem definir suas linhas de formação específicas, apresentando uma identidade mais precisa e marcada para o profissional de relações públicas". Em outra parte do documento, quando se faz referência à seleção e organização dos conteúdos, no item "Práticas laboratoriais", também há uma referência à redação institucional para mídias digitais. Elias Machado e Marcos Palacios (2007, p. 280) alertaram para o cuidado que se deve ter para não limitar as questões tecnológicas apenas a incorporá-las, mas também para assumir uma visão crítica sobre as mesmas:

(...) necessidade de evitar a simples incorporação das novas tecnologias para uso meramente instrumental, mas, sim, utilizálas para formação de espaços totalmente diferenciados de ensino, em laboratórios onde se busque muito mais que a simples reprodução de conhecimento, para atingir o objetivo de uma instituição universitária que é a produção do conhecimento.

Margarida Kunsch (2007, p. 90), por sua vez, ressaltou a responsabilidade que recai sobre as instituições de ensino e os cursos, que precisam estar atentos ao que representa o cenário digital: "As possibilidades existentes na produção de mídias alternativas nos segmentos do impresso, do eletrônico, do audiovisual e do digital constituem uma realidade que precisa ser encarada nos processos de formação universitária". Um curso que pretende formar seus alunos para uma realidade na qual possam exercer a profissão deve conhecer e ensinar as práticas que estão sendo aplicadas.

Já Elizabeth Saad Corrêa (2008, p. 201) fez uma crítica ao modelo de ensino superior em comunicação social no país, tanto pela legislação do Ministério da Educação quanto pelos vícios das instituições de ensino:

Se considerarmos o panorama das IES brasileiras, a formação de profissionais de comunicação está determinada, e em muitos casos engessada, pelas definições do currículo mínimo do MEC; ou pela forma de gestão dos cursos e das grades curriculares dentro das IES, arraigadas a aspectos culturais internos da instituição, geralmente pouco afeitos à inovação.

Ou seja, é preciso inovar, a começar pelos cursos e docentes. Muitas vezes a maior barreira está na falta de qualificação docente para esse cenário, o que, consequentemente, se reflete no ensino (com a lacuna para o digital). Claudia Peixoto de Moura (2010, p. 01) destacou os vários modelos de ensino que são possíveis, com o olhar no mercado, na pesquisa e em algumas características que envolvem uma boa formação. Ela defendeu a necessidade de ampliar a discussão sobre as atividades do campo da comunicação: "Uma boa formação envolve criatividade, conceituações, idiomas, redação, atitude empreendedora, entre outras características. Existe a necessidade de um profissional de comunicação com formação ampla". A autora sugeriu ainda uma ampla discussão sobre o perfil que se quer para o profissional de relações públicas, sobre a função do ensino de comunicação no Brasil e, ao mesmo tempo, os desafios que isso representa para os cursos e para as IES.

A sociedade está numa era em que as transformações em relação ao saber ocorrem de maneira acelerada. Como relatou Pierre Lévy (1999, p. 157), "a maioria das competências adquiridas por uma pessoa no início de seu percurso profissional estarão obsoletas no fim de sua carreira". Atualmente, esse ritmo (constante avanço) já ocorre no período de realização de um curso superior de quatro anos, em média, na área de relações públicas, no Brasil. 
Não se pode esquecer que o curso superior prepara o acadêmico para uma profissão. Sendo assim, a maioria dos egressos pretende ser absorvida pelo mundo do trabalho. Não há dados específicos de relações públicas, mas da área ampla da comunicação social. As informações são de uma pesquisa organizada pelo Ipea, elaborada por vários autores. Entre eles, Maria Cristina Gobbi (2010) apresenta dados apontando que apenas 2,6\% do total de formandos em comunicação social, no Brasil, de 2000 a 2008, tiveram inserção no campo da pesquisa. Ou seja, 97,4\% dos graduados em comunicação social atuam no mundo do trabalho, fora da pesquisa/ensino/docência, de acordo com a pesquisa ${ }^{4}$.

Ivone de Lourdes Oliveira (2008, p. 56) observou que o ensino superior deve preparar os futuros profissionais para o que eles efetivamente vão enfrentar. Porém, não é o mercado que deve ditar as regras às instituições e aos cursos. Por isso, a autora defendeu uma visão intermediária, na qual há uma formação equilibrada (científica e profissional) dos egressos:

A universidade tem de se preocupar com a preparação de profissionais para atuarem no mundo do trabalho, mas nunca na perspectiva de adestramento, que reforça a ideia de formação referendada pela repetição do que já é praticado (...). Sua contribuição é mais significativa, no sentido de construir estratégias que facilitem aos estudantes enfrentar as mudanças e desafios no decorrer de sua vida pessoal e profissional.

A autora destacou mudanças no mundo do trabalho e as consequências que trazem para a atuação do profissional relações públicas, como o surgimento de novas profissões, a supressão de algumas e a necessidade de adaptações de outras. Oliveira (2008, p. 60) também explicou que essas mudanças ocorrem porque

um mundo em mudanças torna as escolhas profissionais cada vez mais precárias e difíceis. Podemos dizer, então, que não existem mais identidades profissionais fixas, uma vez que vão tomando formas diferenciadas, de acordo com as transformações que ocorrem, outras novas surgiram e outras demandas estão aparecendo, o que vem demonstrar a existência de metamorfoses profissionais.

Oliveira (2008, p. 62) complementou que o profissional com uma formação mais ampla e sólida, estará mais preparado para ocupar melhores espaços no mundo do trabalho:

Está comprovado que o mundo do trabalho quer profissionais dotados de capacidade crítica e de espírito de colaboração. Um profissional com bagagem humanística estará mais preparado para compreender a complexidade da sociedade global e transnacional e terá maior competência analítica para entender e atuar na sociedade repleta de mudanças.

No contexto organizacional com as constantes mudanças tecnológicas se exigem profissionais da comunicação atentos a essas transformações. As relações públicas digitais, entendidas como todo o cenário digital que está inserido na prática da área, tornam-se importantes para a efetivação de melhor e maior interação entre sociedade e organizações (nãogovernamentais, privadas ou públicas), que propiciem novos fluxos e trocas de informações entre essas instituições e seus públicos de interesse.

A questão central é a indispensável inserção de disciplinas e projetos que contemplem as novas tecnologias na estrutura curricular do curso de relações públicas. De acordo com Lidiane Ramirez de Amorim (2009, p. 85),

inovações tecnológicas desencadeiam novas formas de comunicar, novas apropriações e novos efeitos para os quais as teorias clássicas já não dão conta. No entanto, ainda que a concepção funcionalista da comunicação pareça ter sido superada, o critério elementar de transmissão e recepção de mensagens ainda aparece como indicador de eficiência do ato comunicativo.

4 Analisando o total de egressos de 2000 a 2008 e a previsão de formandos para 2009 (já que a pesquisa foi encerrada antes). 
Ricardo Freitas (2002, p. 07) salienta que existe urgência em estudar novas perspectivas resultantes da informatização para as áreas da comunicação social e das relações públicas: "Fenômenos de nosso tempo, como a globalização da economia, a informatização do cotidiano urbano e a multiplicidade de serviços, possibilitaram um enorme leque de novas questões sobre a comunicação social e suas habilitações". Os aspectos apontados pelo autor precisam de atenção na formação do comunicólogo.

Silvana Maria Sandini (2010, p. 88) reforçou a importância da preparação para as novas tecnologias em relações públicas argumentando que

as atividades de relações públicas vêm se desenvolvendo em um cenário de constantes mudanças. Percebe-se aí a necessidade de atualização dos profissionais às novas tecnologias, que modificam o relacionamento organização-públicos.

É importante a adequação da profissão de relações públicas às novas demandas que o mundo do trabalho espera dos profissionais formados. Se não contempladas com habilidades e competências ${ }^{5}$ durante a formação acadêmica, outras profissões atuarão nessas áreas de sombreamento ${ }^{6}$, ocupando espaços de trabalho de relações públicas, que, porém, ainda não foram incorporadas efetivamente nas práticas do ensino superior da área.

0 currículo e o projeto pedagógico do curso (PPC) são o primeiro aspecto que precisa dimensionar os focos de atuação, tanto no curso quanto no perfil do egresso pretendido. Nesse contexto Cicilia Peruzzo (2003, p. 132) recomendou cuidado com as habilidades e competências nas estruturas propostas:

1. 0 currículo: é aconselhável que ele tenha espaços flexíveis para atividades diferenciadas - para além das ações formais em sala de aula - e complementares às aulas expositivas e livros didáticos. Quanto à flexibilidade, é recomendável que uma parte das atividades curriculares possa ser desenvolvida na forma de projetos especiais de extensão e de pesquisa, possibilitando ultrapassar os muros do espaço universitário. Atividades complementares seriam, por exemplo: uso do rádio na escola e/ou na comunidade, engajamento em projetos de pesquisa de iniciação científica e em projetos de leitura, assessoria de comunicação a entidades sociais sem fins lucrativos, etc. 2. Projeto pedagógico: a estrutura curricular é apenas uma parte de uma proposta mais ampla de curso que é expressa no projeto pedagógico, o qual contempla os princípios pedagógico-filosóficos, traça o perfil almejado do graduado, levanta as características do contexto onde a instituição se localiza, elenca as características requeridas do corpo docente e traça parâmetros didático-pedagógicos e de infraestrutura (laboratórios, biblioteca, etc).

Já Oliveira (2008, p. 62) sustentou que o olhar no mercado e nas novas tecnologias devem ser acompanhadas de uma visão geral, sempre compartilhando os saberes teóricos e práticos:

Como educadores, temos a obrigação de continuar problematizando a formação do comunicador e reforçar o estudo das humanidades que proporcione o entendimento de mundo. Por se constituir num campo em construção, a comunicação precisa investir em produção científica e construções conceituais que abram oportunidades de rever práticas, metodologias e comportamentos, visando ao crescimento e à consciênciado nosso "saber" teórico e prático.

Kunsch (2007, p. 90) ressaltou que são muitas as perspectivas de atuação no cenário digital para os profissionais e, consequentemente, também são grandes "as possibilidades existentes na produção de mídias alternativas nos segmentos do impresso, do eletrônico, do audiovisual e do digital que constituem uma realidade que precisa ser encarada nos processos de formação universitária".

5 Aqui no artigo entendido como o processo envolvendo o aprender uma profissão no contexto educacional do ensino superior.

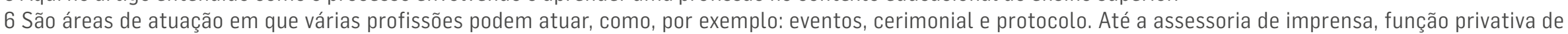

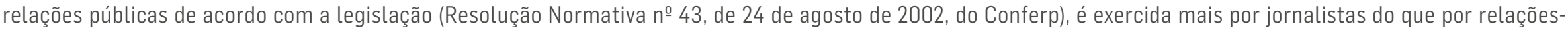
públicas no Brasil, segundo pesquisa feita pela Associação Brasileira de Comunicação Empresarial (Aberje) em 2007. 
Nos cursos de comunicação social, no Brasil, a questão digital é objeto de estudo há mais de uma década na área de jornalismo, sendo tema de pesquisa de Elias Machado. Segundo ele, os primeiros textos resultantes de pesquisas relacionadas com a incorporação das tecnologias digitais no ensino de jornalismo são de 2002. Por um lado, existe, entre os agentes envolvidos na formação dos futuros profissionais, crescente percepção de que os estudantes de comunicação precisam ter uma formação que atenda às novas demandas geradas pelos processos de digitalização da informação. Por outro, persistem posições divergentes em pontos como, por exemplo, o tipo de impacto que esses processos provocarão na formação e, até mesmo, na continuidade das profissões do campo da comunicação. São questões que se colocam aos pesquisadores, professores e profissinais. Na área de relações públicas digitais, no que se refere ao ensino, há uma grande lacuna de pesquisa.

Os impactos que o foco digital traz e continuará trazendo ao ensino ainda não podem ser mensurados em plenitude. Porém, em termos de ocupação profissional no mundo do trabalho, já é possível, com base em pesquisas ${ }^{7}$, ver que há um avanço de outras áreas do conhecimento (fora de relações públicas) na atuação e no gerenciamento dos processos comunicacionais no país. A universidade, por sua função de analisar criticamente o mundo existente e as suas condições, pode identificar demandas que não estão ainda formalizadas como profissões. Mas determinadas ações podem ser agregadas pelas profissões já existentes, como é o caso das relações públicas digitais.

A inserção, mais incisiva desse digital no ensino superior da área de relações públicas também exige, do corpo docente, preparação adequada, aspecto que merece mais reflexão e estudo, porém não é o foco deste artigo. Além de elevada qualificação intelectual e domínio de saberes na área, com os novos paradigmas da educação, o professor, cada vez mais, tem papel importante na condução de estudos, pesquisas e atividades que auxiliem na construção do conhecimento do aluno.

Os gestores e professores dos cursos de relações públicas precisam discutir o impacto que o cenário digital traz aos egressos e dimensionar a inserção de maneira mais efetiva no ensino superior da área.

\section{CONSIDERAÇÕES FINAIS}

O XXXV Congresso Brasileiro de Ciências da Comunicação, da Sociedade Brasileira de Estudos Interdisciplinares da Comunicação (Intercom) ${ }^{8}$, realizado em 2012, discutiu os desafios acadêmicos do ensino de comunicação no Brasil, no subevento Encontro sobre o ensino de comunicação (Ensicom). A área de relações públicas estava representada pela professora Margarida M. Krohling Kunsch, que discorreu sobre a importância das Diretrizes Curriculares Nacionais, de 2013. A pesquisadora ressaltou a necessidade de "ampliar a qualificação de professores de relações públicas, com participação em congressos, e da oferta de aulas mais práticas, não tão teóricas".

É notável o descompasso entre o que se ensina e o que é esperado do egresso no mercado. A reflexão sobre mudanças no ensino da área torna-se necessária para compreender a inserção dos indivíduos em um universo cultural, econômico, político e, principalmente, tecnológico jamais visto. Não se trata de uma visão que pretende atrelar a formação ao que o mercado quer, mas, sim, capacitá-la a proporcionar aos acadêmicos uma aptidão para o exercício das funções que são características da área, que trazem novas configurações e necessidades com o avanço das tecnologias digitais.

7 Pesquisa "Comunicação interna" - Aberje. 2007. Disponível em: <www.aberje.com.br/pesquisa/pesquisa_Com_Interna_2007.pdf>. Outra pesquisa foi realizada pela mesma associação em 2010: "Estudo de remuneração da comunicação organizacional - 2010 >> Disponível em: <http://www.aberje.com.br/pesquisa/pesq_Aberje_ remun_2010.pdf>. Acesso em: 31 jan. 2012.

8 Ver portal da Intercom: <http://www.portalintercom.org.br>. 
As mudanças tecnológicas colocam exigências para todas as profissões e, de modo particular, também para as relações públicas. É a universidade que faz (deveria fazer) a mediação para a apropriação dos conhecimentos científicos necessários à formação profissional e social do sujeito. A sociedade, por outro lado, requer dos indivíduos, a todo momento, adaptação às transformações tecnológicas e aprendizado de conceitos básicos da sua área de formação.

Nestes 47 anos de ensino de relações públicas que se completam em 2014, no Brasil, muitas foram as mudanças que ocorreram e maiores ainda são os desafios que estão postos. Com o investimento público dispensado ao ensino superior nos anos 2000, a expansão é visível, quantitativamente ${ }^{9}$. Com isso, mais pessoas têm acesso ao ensino superior e a média de pontuação necessária do Enem ${ }^{10}$ tem diminuído, pois as vagas triplicaram no país nos últimos catorze anos, segundo 0 Ministério da Educação (MEC).

0 mundo do trabalho apresenta novos problemas, novas áreas de atuação, novas exigências e, ao mesmo tempo, vagas para quem tiver preparo. Estes são alguns dos dilemas do ensino superior expostos, diariamente, aos gestores, professores e educadores. Aos cursos superiores compete formar cidadãos críticos, com domínio profissional da sua área de atuação.

Com base nas considerações sobre a evolução dos mercados e o avanço das tecnologias digitais, as relações públicas digitais e a sua incorporação no ensino da área, em termos de produção de conhecimento, foram avaliadas com um decréscimo nos últimos anos. Além disso, no Brasil, ainda não foi alcançada uma significativa inserção dos profissionais nas áreas estratégicas de comunicação das organizações.

0 ensino superior é o que prepara ou deveria preparar esses profissionais para o mundo do trabalho. 0 que se defende neste artigo é que o ensino superior na área incorpore mais substancialmente o cenário digital como uma perspectiva de atuação e ampliação de mercado para os egressos. Com essa adequação, certamente se amplia a possibilidade de inserção dos profissionais, o que, consequentemente, aumentará a procura pela área, podendo assim, melhorar o cenário atual no Brasil, onde cerca de quarenta cursos de graduação de relações públicas não foram mais ofertados na última década, por falta de demanda.

\section{REFERÊNCIAS}

AMORIM, Lidiane Ramirez de. Telespectador multimídia: olhares sobre o jornalismo participativo em noticiários de TV. 2009. 170 f. Dissertação (Mestrado em Comunicação) - Faculdade de Comunicação Social, PUC-RS, Porto Alegre, 2009.

CORRÊA, Elizabeth Saad. Estratégias 2.0 para a mídia digital: internet, informação e comunicação. 2. ed. São Paulo: Senac, 2008.

FREITAS, Ricardo. Desafios contemporâneos à eficiência das relações públicas. In: FREITAS, Ricardo; LUCAS, Luciane. Desafios contemporâneos em comunicação: perspectivas de relações públicas. São Paulo: Summus, 2002.

FREITAS, Ricardo; LUCAS, Luciane. Desafios contemporâneos em comunicação: perspectivas de relações públicas. São Paulo: Summus, 2002.

9 Apesar disso, a área de relações públicas não alcançou o índice mínimo de matrículas, segundo o MEC, motivo pelo qual foi dispensada de realizar o Exame Nacional de Desempenho de Estudantes (Enade) em 2012; a realização da prova é opcional para os cursos. Na área da comunicação social, apenas acadêmicos de jornalismo e publicidade e propaganda são obrigados a realizar o exame.

10 Exame Nacional do Ensino Médio, que dá acesso ao ensino superior no Brasil em grande parte das universidades federais. 
GOBBI, Maria Cristina. Panorama da produção de conhecimento em comunicação no brasil. In: CASTRO, Daniel; MARQUES DE MELO, José; CASTRO, Cosette Castro (Org.). Panorama da comunicação e das telecomunicações no Brasil. Vol. 3. Brasília: Ipea, 2010. Disponível em: <http://www.ipea.gov.br/portal/images/stories/PDFs/Panorama_da_Comunicao_e_ das_Telecomunicaes_no_Brasil_-_Volume_3.pdf>.Acesso em: 30 jan. 2012.

GONÇALVES, Fernando do Nascimento. Relações públicas e as novas tecnologias: solução ou dilema? In: FREITAS, Ricardo F.; LUCAS, Luciane (Org). Desafios contemporâneos em comunicação: perspectivas de relações públicas. São Paulo: Summus, 2002.

KUNSCH, Margarida M. Krohling, Perspectivas e desafios para as profissões de comunicação no terceiro milênio. In: KUNSCH, Margarida M. Krohling (Org.). Ensino de comunicação: qualidade na formação acadêmico-profissional. São Paulo: ECA-USP; Intercom, 2007. p. 87-101.

(Org.). Ensino de comunicação: qualidade na formação acadêmico-profissional. São Paulo: Intercom, 2007.

FIGUEIREDO, Rubens (Org.). Marketing político em tempos modernos. Rio de Janeiro: Konrad-Adenauer-Stifung, 2008.

LÉVY, Pierre. Cibercultura. São Paulo: Editora 34, 1999.

MACHADO, Elias G. 0 ensino de jornalismo em tempos de ciberespaço. In: MACHADO, Elias; PALACIOS, Marcos (Org.). 0 ensino de jornalismo em redes de alta velocidade: metodologias \& softwares. Salvador: EDUFBA, 2007. p. 11-22.

MEC. Ministério da Educação. Diretrizes Curriculares nacionais para os cursos de relações públicas. Resolução no 02, de 27 de setembro de 2013. Diário Oficial da União, Brasília, p.28-29, 01 out. 2013. Disponível em: <http://pesquisa.in.gov.br/ imprensa/jsp/visualiza/index.jsp?data=01/10/2013\&jornal=1\&pagina=28\&totalArquivos=96> Acesso em: 02 out. 2013.

MORAES, Claudia Herte de. Apontamentos sobre o contexto do ensino superior. Revista do Conselho de Reitores das Universidades Brasileiras - CRUB, Brasília, v. 28, n. 56 e 57, p. 13-29, jan./dez. 2006.

MOURA, Cláudia Peixoto de. 0 ensino de relações públicas. 2010. Disponível em:<http://www.rp-bahia.com.br/claudiamoura4. htm>. Acesso em: 22 jul. 2010.

OLIVEIRA, Ivone de Lourdes. Formação acadêmico-profissional em ambiente de mudanças: desafios pedagógicos. In: MOREIRA, Sonia Virginia; VIEIRA, João Pedro Dias (Org.). Comunicação: ensino e pesquisa. Rio de Janeiro: Eduerj, 2008.

PÉREZ GÓMEZ, Ángel I. Competências ou pensamento prático? A construção dos significados de representação e de ação. In: SACRISTÁN, José G. et al. Educar por competências: o que há de novo? Trad. de Carlos Henrique Lucas Lima. Porto Alegre: Artmed, 2011.

PERUZZO, Cicília Maria Krohling. Tópicos sobre o ensino de comunicação no Brasil. In: PERUZZO, Cicília Maria Krohling; SILVA, Robson Santos (Org.). Retrato do ensino em comunicação no Brasil. São Paulo: Intercom; Taubaté: Unitau, 2003.

PERUZZO, Cicília Maria Krohling; SILVA, Robson Santos (Org.). Retrato do ensino em comunicação no Brasil. São Paulo: Intercom; Taubaté: Unitau, 2003.

SANDINI, Silvana Maria. O blog corporativo como interface no gerenciamento da impressão. 2010. 506 f. Dissertação (Mestrado em Comunicação) - Faculdade de Comunicação Social, PUC-RS, Porto Alegre, 2010.

Artigo recebido em 26.02.2014 e aprovado em 29.04.2014. 